\title{
Analysis of the Virtual Power Plant Model Based on the Use of Emergency Generators in South Korea
}

\author{
Beom Jin Chung*, Chang Seob Kim** and Sung-Yong Son ${ }^{\dagger}$
}

\begin{abstract}
This study analyzes the economic efficiency of the virtual power plant (VPP) model that aims to integrate a number of emergency generators installed at the consumer end and operate them as a single power plant. Several factors such as the demand response benefits from VPP operation and costs incurred for converting emergency generators into VPP are considered to assess the economic efficiency of the proposed VPP model. Scenarios for yearly VPP conversion are prepared based on the installed capacities of the emergency generators distributed in South Korea, while the costs and benefits are calculated from the viewpoints of participants and power companies in accordance with California Test Methods. Furthermore, a sensitivity analysis is conducted on the cost factors among those affecting the economic efficiency of VPP business because these two factors have a great impact on benefits.
\end{abstract}

Keywords: Virtual power plant, Emergency generator, Economic analysis

\section{Introduction}

An emergency generator is a separate power supply unit for temporarily supplying power to main facilities when the commercial power source is cut off because of electrical accidents such as open and short circuits and power outage. Therefore, emergency generators are typically separated from the system, making it unnecessary to consider a system interconnection. The virtual power plant (VPP) model, which aims to integrate dispersed resources such as emergency generators, energy storage systems, and new and renewable energy, is a comprehensive concept that includes conventional demand response. VPP also aims to utilize demand-side electric power resources by acknowledging their equal footing as power-generating resources. From a technical standpoint, VPP is usually defined as a system that operates a single VPP by integrating numerous dispersed power sources. From technology and market perspectives, VPP is defined as a system or structure that combines dispersed resources through a real-time linkage to make them tradable $[1,2]$. This study analyzes the economic efficiency of power generation from emergency generator resources based on the VPP concept in South Korea. The economic efficiency analysis is based on California Test Methods.

In this study, demand management programs, emergency generator status, and utilization as demand resources are considered to derive a benefit/cost $(\mathrm{B} / \mathrm{C})$ model. The

$\dagger$ Corresponding Author: Dept. of Electrical Engineering, Gachon University, Korea. (xtra@gachon.ac.kr)

* Smart Green Home Research Center, Gachon University, Korea. (bjchung@gachon.ac.kr)

** Dept. of Energy IT, Gachon University, Korea

(cskim407@gachon.ac.kr)

Received: June 25, 2015; Accepted: September 15, 2015 presented analysis has three stages. First, we analyze the resource capacity that can be ensured by investment if the conversion of the emergency generator into VPP expands to include all emergency generators. Second, the costs and benefits incurred according to annual distribution rate scenarios are calculated. In addition, the net present value (NPV) of economic efficiency is assessed from the perspectives of VPP service providers and power companies, considering all the benefits associated with operation as well as the distribution and operation costs incurred for distributing emergency generators. Lastly, a sensitivity analysis is carried out in relation to price and cost changes.

\section{Emergency Generator-base VPP Cost Model}

\subsection{Status of emergency generators in south korea}

Studies have measured emergency generator utilization in South Korea by conducting surveys and investigating cost items such as the remodeling cost required for the utilization of demand response resources [3-5]. Previous studies have mainly been based on load management models from the perspective of power companies; however, one study has applied a VPP model [6]. According to this study's findings, 63,185 emergency generators were installed across the county in 2013 with a total generator capacity of about $19.3 \mathrm{GW}$. Among these, 52,800 emergency generators had a capacity of $500 \mathrm{~kW}$ and lower, accounting for about $10 \mathrm{GW}$, while 9,904 generators had a capacity of $500 \sim 2,500 \mathrm{~kW}$, accounting for about $4.2 \mathrm{GW}$. Further, 248 emergency generators had a capacity of $2,500 \mathrm{~kW}$ and 


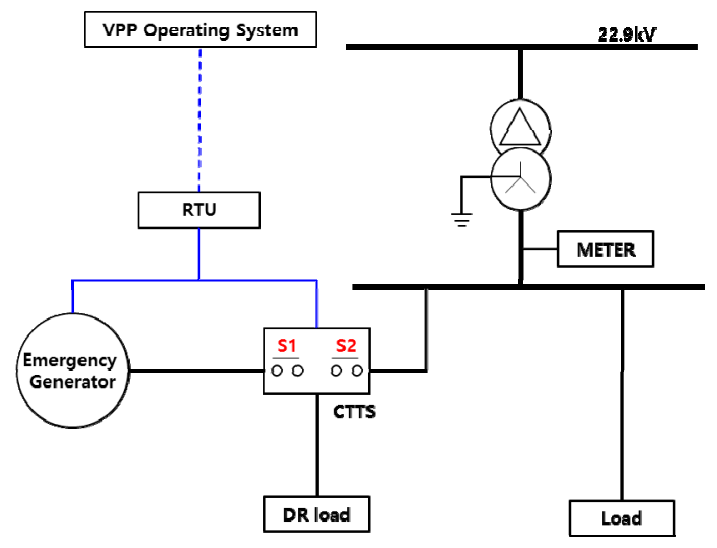

Fig. 1. Remodeling of emergency generators for VPP Configuration

higher, accounting for about 5.1 GW.

\subsection{Emergency generator configuration and re- modeling for VPP application}

Emergency loads normally operate by being connected to the system side; however, in emergencies, loads are connected to the emergency generator side to ensure a power supply. At this point, an automatic transfer switch (ATS) is commonly used to transfer loads. Since the ATS acts as a simple switch, the load will experience a power outage if transferred to the emergency generator side for non-emergencies. While this does not cause major problems if used only in an emergency, it may cause inconvenience for users if employed frequently in other situations such as for demand response.

A Closed Transition Transfer Switch (CTTS), unlike an ATS, operates the generator in advance to establish the synchronization condition for voltage and frequency of the generator power and system power before briefly transferring the load to the emergency generator side through a parallel operation stage. Since the CTTS supports load transfer without incurring a power outage, it can minimize user inconvenience and ease the electrical burden imposed on the loads or generators. In many cases, the existing generator and its peripheral equipment must be remodeled to operate a power system selectively for the VPP support using the CTTS because of the difficulties involved in the VPP configuration (i.e., real-time monitoring and operation) because most existing generators are outdated and lack a digitalized control function. Typical costs include the emergency generator remodeling cost for the CTTS control as well as additional costs for the CTTS control panel. Moreover, emergency generators are generally only connected to emergency loads in a building and thus the generator output is determined by the load. The load ratio is commonly lower compared with the emergency generator capacity, which means that only a part of the emergency generator capacity is available to use. This limitation hampers the effective use of emergency
Table 1. Potential capacity and remodeling cost of emergency generators for generators with different capacities

\begin{tabular}{c|c|c|c|c}
\hline \multirow{2}{*}{$\begin{array}{c}\text { Generator } \\
\text { capacity }\end{array}$} & \multicolumn{2}{|c|}{$\begin{array}{c}\text { Load relocation not } \\
\text { included }\end{array}$} & \multicolumn{2}{c}{$\begin{array}{c}\text { Load relocation } \\
\text { included }\end{array}$} \\
\cline { 2 - 5 } & $\begin{array}{c}\text { Potential } \\
\text { capacity } \\
(\mathrm{MW})\end{array}$ & $\begin{array}{c}\text { Remodeling } \\
\text { price } \\
(\mathrm{KRW} / \mathrm{kW})\end{array}$ & $\begin{array}{c}\text { Potential } \\
\text { capacity } \\
(\mathrm{MW})\end{array}$ & $\begin{array}{c}\text { Remodeling } \\
\text { price } \\
(\mathrm{KRW} / \mathrm{kW})\end{array}$ \\
\hline $150 \sim 300 \mathrm{~kW}$ & 1,897 & 287,328 & 3,122 & 219,648 \\
\hline $300 \sim 500 \mathrm{~kW}$ & 1,669 & 220,423 & 2,734 & 168,968 \\
\hline $500 \sim 1000 \mathrm{~kW}$ & 1,386 & 156,820 & 2,134 & 126,002 \\
\hline $1000 \sim 2000 \mathrm{~kW}$ & 322 & 114,520 & 478 & 93,557 \\
\hline $2000 \mathrm{~kW}$ and higher & 1,261 & 80,895 & 1,652 & 71,742 \\
\hline Total & 6,535 & - & 10,120 & - \\
\hline
\end{tabular}

generator resources. Therefore, for the efficiency of investment, the load ratio connected with the emergency generator must be raised through load relocation, which incurs additional costs associated with the load transfer.

\subsection{Status of emergency generator resources in south korea and economic analysis models of VPP}

\subsubsection{Status of emergency generator resources and remodeling cost:}

The potential capacity that an emergency generator can contribute to building an emergency generator-based VPP must be calculated. As shown in Table 1, the potential VPP capacity of emergency generators in South Korea as of 2012 was proposed for generators with different capacities along with the prices related to remodeling [6]. Here, total potential capacity based on the loads connected to the current emergency generators was estimated to reach 6,535 MW and $10,120 \mathrm{MW}$ if the load ratio is increased by relocating the load of emergency generators.

\subsubsection{Avoided Cost of Equipment:}

From the perspective of the electric power system, extra power generation capacity can be obtained in the system through the operation of the emergency generator from the consumer end. The avoided cost of equipment is the cost that would have been incurred by delaying the construction of electric power lines or additional generation equipment with extra generating capacity. The annual avoided cost of equipment can be calculated as follows:

$$
\begin{aligned}
& \text { Avoided cost of equipment }[K R W-\text { year }] \\
& =\text { cummulative annual deployment capacity of } E G \\
& \times \text { average annual load sharing rate } \\
& \times \text { average annual response rate } \\
& \times \text { unit price of avoided cost }[K R W / \mathrm{kW}-\text { year }]
\end{aligned}
$$

where $E G$ is Emergency generators.

\subsubsection{Avoided cost of purchased power:}

The purchased power cost represents the cost incurred 
by power companies when they purchase electricity in the wholesale power market to sell on. From the perspective of the electric power system, this cost is the avoided cost generated by the reduced volume of electricity purchased in the wholesale power market because of the decrease in demand for power from the consumer end. Since the system marginal price (SMP) varies depending on the time of day and season, the avoided cost of purchased power for electricity purchased in the market is incurred if power consumption is reduced during peak times with a high SMP or if the loads are operated by avoiding such peak times. In this study, the time-based SMP posted by the Korea Power Exchange in 2012 was selected as the price of purchased power [7]. The annual avoided cost of purchased power can be calculated as follows:

$$
\begin{aligned}
& \text { Annual avoided cost of purchased power } \\
& =\sum_{n=1}^{12} S M P_{n} \cdot \begin{array}{l}
\text { reduced power by VPP based backup } \\
\text { generators }
\end{array}
\end{aligned}
$$

\subsubsection{Avoided cost of purchased power because of a reduction in the SMP:}

The development of the VPP-based emergency generator reduces the effect of the power purchased by power companies as well as affects the SMP and helps change the purchased power price during the corresponding period. In this study, the SMP variations for each month were modeled in a linear function. The avoided cost of purchased power because of an SMP reduction was modeled as follows:

Avoided cost of purchased power considering SMPChanges

$$
=\sum_{i=1}^{12} F(i) \times \Delta V_{i} \times V_{i}
$$

where $F(i)$ represents the monthly calculated purchased power considering SMP changes, $\Delta V_{i}$ represents the changes in purchased power volume because of the introduction of the VPP-based emergency generator in the corresponding month, and $V_{i}$ signifies the purchased power volume for the corresponding month.

\subsubsection{Emergency generator fuel cost:}

From the perspective of power companies, flagging demand for electricity because of the operation of VPPbased emergency generators can be represented as a reduction in purchased power in the wholesale market. However, at the consumer end, this leads to an increase in the fuel cost incurred by operating emergency generators.

\subsubsection{Price reduction benefits:}

From the perspective of VPP service providers parti- cipating in the emergency generator-based VPP model business, a power supply reduction from the electric power system because of the operation of emergency generators results in an electricity charge reduction.

\subsubsection{Demand response participation incentives:}

One of the typical business models for VPP service providers is to participate in the demand response business. Participants in the emergency generator-based VPP business register in advance the capacity available for the reduction and must comply with the instructions for reduction to be rewarded.

\subsubsection{Cost for management system construction when distributing the emergency generator-based VPP:}

In order for VPP service providers to manage VPP model emergency generators, costs for developing and operating a management system are inevitable. The costs incurred for system construction include a cost for constructing a host system to remotely manage the emergency generators and a cost for emergency generator management terminal equipment. The operating costs of VPP service providers are divided into system operating costs and business management costs. System operating costs consist of labor costs, system maintenance costs, data center rack rental fees, data center line/circuit fees, and SMS fees. Business management costs consist of labor costs and miscellaneous costs.

\section{Simulation and Discussion}

\subsection{Simulation scenario}

According to the 2012 Korea Electrical Safety Corporation's research, the total installed capacity of emergency generators in South Korea as of August 2012 was around $20 \mathrm{GW}$ and this continues to increase by 2.5 GW every year [6]. Emergency generator distribution scenarios were classified into three categories: conservative, standard, and proactive. The conservative scenario was set to have a distribution rate $33 \%$ lower than that in the standard scenario, while the proactive scenario had a distribution rate $33 \%$ higher than that in the standard scenario. In the standard scenario, distribution capacity is 3,756 MW in 2030 as shown in Table 2, which was set in reference to the sixth basic plan for electricity demand and supply in South Korea [8]. Since demand management technology based on smart grids such as VPP lacks the necessary technologies, solutions, and systems in the initial stage of distribution, it was set to have a distribution curve with a full-scale expansion from 2020 (i.e., after the advanced stage of distribution), rather than in its initial stage. The cumulative annual emergency generator distribution capacity to be converted into VPP resources 
Table 2. Cumulative annual distribution capacity of VPPconverted emergency generators (MW)

\begin{tabular}{c|c|c|c}
\hline \multirow{2}{*}{ Year } & \multicolumn{3}{|c}{ Scenario } \\
\cline { 2 - 4 } & Conservative & Standard & Proactive \\
\hline 2015 & 16.7 & 25.0 & 33.3 \\
\hline 2016 & 41.7 & 62.5 & 83.3 \\
\hline 2017 & 75.0 & 112.5 & 150.0 \\
\hline 2018 & 116.7 & 175.0 & 233.3 \\
\hline 2019 & 166.7 & 250.0 & 333.3 \\
\hline 2020 & 241.7 & 362.5 & 483.3 \\
\hline 2021 & 358.3 & 537.5 & 716.7 \\
\hline 2022 & 541.7 & 812.5 & $1,083.3$ \\
\hline 2023 & 762.5 & $1,143.8$ & 1525.0 \\
\hline 2024 & $1,004.2$ & $1,506.3$ & $2,008.3$ \\
\hline 2025 & $1,254.2$ & $1,881.3$ & $2,508.3$ \\
\hline 2026 & $1,504.2$ & $2,256.3$ & $3,008.3$ \\
\hline 2027 & $1,754.2$ & $2,631.3$ & $3,508.3$ \\
\hline 2028 & $2,004.2$ & $3,006.3$ & $4,008.3$ \\
\hline 2029 & $2,254.2$ & $3,381.3$ & $4,508.3$ \\
\hline 2030 & $2,504.2$ & $3,756.3$ & $5,008.3$ \\
\hline
\end{tabular}

was then calculated (see Table 2). The cumulative distribution capacity of emergency generators shown in Table 2 is based on their installed capacity, while actual capacity converted into VPP resources is determined by the load capacity acquired with load modification.

The load ratio obtained through load relocation in the scenario presented in this study was set to $50 \%$. The response operation ratio is the rate at which a participating customer that owns an emergency generator comes to operate the generator at the request of the VPP service provider, which varies according to the degree of the customer's response and capability of the VPP service provider. The emergency generator is owned by the customer, not the VPP service provider, and the generator equipment is not subject to regular maintenance. Therefore, it is not practical to estimate the response operation ratio at $100 \%$. In this study, the response operation ratio was set to $80 \%$, while the number of yearly operations was set to 60 based on the electricity market operating regulations announced in 2014 [9].

\subsection{Costs and benefits by factor}

\subsubsection{Emergency generator remodeling cost for VPP:}

For emergency generators converted into the VPP model, a cost for load transfer and a cost to modify the CTTS are required. In the emergency generator remodeling cost, the remodeling price per $\mathrm{kW}$ decreases as the installed capacity of the generator increases [6]. This study assumed that an emergency generator with a capacity of $750 \mathrm{~kW}$ and higher will be converted into the VPP model, taking cost effectiveness into consideration. Furthermore, a remodeling price of $93,146 \mathrm{KRW} / \mathrm{kW}$ was applied to generators with a capacity of $750 \mathrm{~kW}$ and higher, which is the average remodeling price for such generators when more than 100 emergency generators are modified,

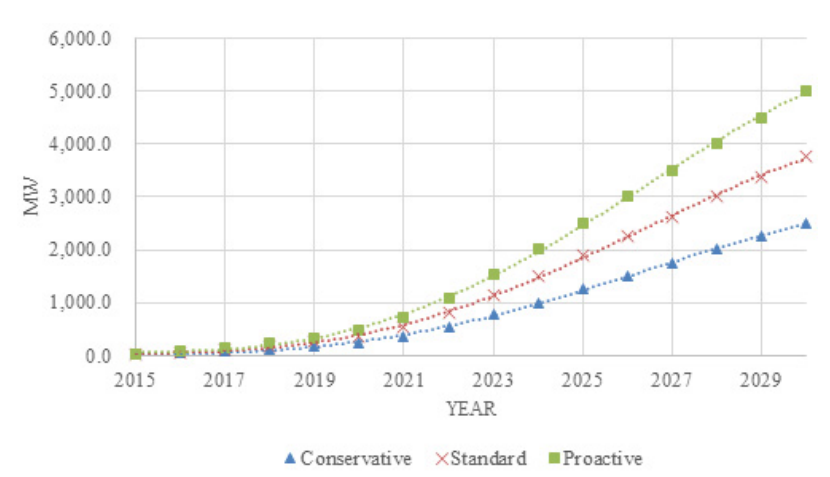

Fig. 2. Yearly remodeling cost according to the distribution scenarios (Million KRW)

according to 2012 Korea Electrical Safety Corporation research [6]. The yearly remodeling costs according to the yearly distribution scenarios are summarized in Fig. 2.

\subsubsection{Avoided Cost of Equipment:}

The unit price of the avoided cost of equipment applied in this study was as follows $[10,11]$ :

$$
\begin{aligned}
& \text { Avoided cost of equipment } \\
& =235,704[\mathrm{KRW} / \mathrm{kW}-\text { year }] \\
& \begin{array}{r}
\text { Avoided cost of generating units } \\
=137,180[\mathrm{KRW} / \mathrm{kW} \text { - year }] \\
\text { Avoided cost of } T / L \text { construction } \\
=98,524[\mathrm{KRW} / \mathrm{kW}-\text { year }]
\end{array}
\end{aligned}
$$

The avoided cost of equipment can be calculated by multiplying the avoided price of equipment by the mandatory reduction registered by the VPP service provider. In this study, the mandatory reduction capacity was a product of the response operation ratio and load ratio as well as the VPP-converted emergency generator installed capacity. Table 3 reports the annual avoided cost of equipment.

Table 3. Annual avoided cost of equipment (Million KRW)

\begin{tabular}{c|c|c|c}
\hline \multirow{2}{*}{ Year } & \multicolumn{3}{|c}{ Scenario } \\
\cline { 2 - 4 } & Conservative & Standard & Proactive \\
\hline 2015 & 2,200 & 3,300 & 4,400 \\
\hline 2016 & 5,500 & 8,250 & 11,000 \\
\hline 2017 & 9,900 & 14,849 & 19,799 \\
\hline 2018 & 15,399 & 23,099 & 30,799 \\
\hline 2019 & 21,999 & 32,999 & 43,998 \\
\hline 2020 & 31,899 & 47,848 & 63,797 \\
\hline 2021 & 47,298 & 70,947 & 94,596 \\
\hline 2022 & 71,497 & 107,245 & 142,994 \\
\hline 2023 & 100,646 & 150,968 & 201,291 \\
\hline 2024 & 132,544 & 198,816 & 265,088 \\
\hline 2025 & 165,543 & 248,314 & 331,086 \\
\hline 2026 & 198,541 & 297,812 & 397,083 \\
\hline 2027 & 231,540 & 347,310 & 463,080 \\
\hline 2028 & 264,538 & 396,808 & 529,077 \\
\hline 2029 & 297,537 & 446,306 & 595,074 \\
\hline 2030 & 330,536 & 495,803 & 661,071 \\
\hline
\end{tabular}


Table 4. Avoided Cost of Purchased Power (Million KRW)

\begin{tabular}{c|c|c|c}
\hline \multirow{2}{*}{ Year } & \multicolumn{3}{|c}{ Scenario } \\
\cline { 2 - 4 } & Conservative & Standard & Proactive \\
\hline 2015 & 66.5 & 99.7 & 132.9 \\
\hline 2016 & 166.2 & 249.3 & 332.3 \\
\hline 2017 & 299.1 & 448.7 & 598.2 \\
\hline 2018 & 465.3 & 697.9 & 930.5 \\
\hline 2019 & 664.7 & 997.0 & $1,329.3$ \\
\hline 2020 & 963.8 & $1,445.7$ & $1,927.5$ \\
\hline 2021 & $1,429.0$ & $2,143.6$ & $2,858.1$ \\
\hline 2022 & $2,160.2$ & $3,240.3$ & $4,320.3$ \\
\hline 2023 & $3,040.9$ & $4,561.3$ & $6,081.7$ \\
\hline 2024 & $4,004.6$ & $6,006.9$ & $8,009.2$ \\
\hline 2025 & $5,001.6$ & $7,502.4$ & $10,003.2$ \\
\hline 2026 & $5,998.6$ & $8,997.9$ & $11,997.2$ \\
\hline 2027 & $6,995.6$ & $10,493.4$ & $13,991.2$ \\
\hline 2028 & $7,992.6$ & $11,988.9$ & $15,985.2$ \\
\hline 2029 & $8,989.6$ & $13,484.4$ & $17,979.2$ \\
\hline 2030 & $9,986.6$ & $14,979.9$ & $19,973.2$ \\
\hline
\end{tabular}

Table 5. Avoided cost of purchased power according to smp changes (Million KRW)

\begin{tabular}{c|c|c|c}
\hline \multirow{2}{*}{ Year } & \multicolumn{3}{|c}{ Scenario } \\
\cline { 2 - 4 } & Conservative & & Conservative \\
\hline 2015 & 102.1 & 2015 & 102.1 \\
\hline 2016 & 255.2 & 2016 & 255.2 \\
\hline 2017 & 459.3 & 2017 & 459.3 \\
\hline 2018 & 714.4 & 2018 & 714.4 \\
\hline 2019 & $1,020.6$ & 2019 & $1,020.6$ \\
\hline 2020 & $1,479.9$ & 2020 & $1,479.9$ \\
\hline 2021 & $2,194.3$ & 2021 & $2,194.3$ \\
\hline 2022 & $3,317.0$ & 2022 & $3,317.0$ \\
\hline 2023 & $4,669.4$ & 2023 & $4,669.4$ \\
\hline 2024 & $6,149.3$ & 2024 & $6,149.3$ \\
\hline 2025 & $7,680.2$ & 2025 & $7,680.2$ \\
\hline 2026 & $9,211.2$ & 2026 & $9,211.2$ \\
\hline 2027 & $10,742.1$ & 2027 & $10,742.1$ \\
\hline 2028 & $12,273.0$ & 2028 & $12,273.0$ \\
\hline 2029 & $13,804.0$ & 2029 & $13,804.0$ \\
\hline 2030 & $15,334.9$ & 2030 & $15,334.9$ \\
\hline
\end{tabular}

\subsubsection{Avoided cost of purchased power:}

The operation profile of the emergency generator is needed to calculate the reduced power consumption in relation to the introduction of VPP-based emergency generators. In this study, the generator was set to operate 60 times per year (10 times per month during summer and winter) and the SMP of peak times in summer and winter was applied in accordance with the 2012 KPX electricity market report [7].

As shown in Table 5, the avoided cost of purchased power is relatively low compared with the avoided cost of equipment. This is mainly because the emergency generator has a limited number and time for single operation.

\subsubsection{Avoided cost of purchased power because of a reduction in the SMP:}

Based on the 2012 KPX electricity market report [7], the avoided costs of purchased power because of an SMP
Table 6. Emergency generator fuel cost (Million KRW)

\begin{tabular}{c|c|c|c}
\hline \multirow{2}{*}{ Year } & \multicolumn{3}{|c}{ Scenario } \\
\cline { 2 - 4 } & Conservative & Standard & Proactive \\
\hline 2015 & 166 & 249 & 332 \\
\hline 2016 & 415 & 623 & 830 \\
\hline 2017 & 747 & 1,121 & 1,494 \\
\hline 2018 & 1,162 & 1,743 & 2,324 \\
\hline 2019 & 1,660 & 2,490 & 3,320 \\
\hline 2020 & 2,407 & 3,611 & 4,814 \\
\hline 2021 & 3,569 & 5,354 & 7,138 \\
\hline 2022 & 5,395 & 8,093 & 10,790 \\
\hline 2023 & 7,595 & 11,392 & 15,189 \\
\hline 2024 & 10,002 & 15,002 & 20,003 \\
\hline 2025 & 12,492 & 18,737 & 24,983 \\
\hline 2026 & 14,982 & 22,472 & 29,963 \\
\hline 2027 & 17,472 & 26,207 & 34,943 \\
\hline 2028 & 19,962 & 29,942 & 39,923 \\
\hline 2029 & 22,452 & 33,677 & 44,903 \\
\hline 2030 & 24,942 & 37,412 & 49,883 \\
\hline
\end{tabular}

Table 7. Electricity charges for general use (B) announced by the korea electric power corporation (KRW)

\begin{tabular}{|c|c|c|c|c|c|c|}
\hline Item & & Flat rate & Time & Summer & $\begin{array}{c}\text { Spring } \\
\text { Autumn }\end{array}$ & Winter \\
\hline IIEn & & $\begin{array}{c}(\mathrm{KRW} / \\
\mathrm{kW})\end{array}$ & 1.IIIE & $\begin{array}{l}\text { (Jul } \\
\text { Aug) }\end{array}$ & - & $\begin{array}{l}\text { (Nov } \\
\text { Feb) }\end{array}$ \\
\hline & & & Light load & 59.1 & 59.1 & 65.3 \\
\hline & I & 6,990 & Medium load & 112.2 & 82.4 & 110.4 \\
\hline $\begin{array}{l}\text { High- } \\
\text { tension }\end{array}$ & & & Max load & 192.5 & 112.4 & 165.6 \\
\hline A & & & Light load & 53.8 & 53.8 & 60 \\
\hline & II & 8,050 & Medium load & 106.9 & 77.1 & 105.1 \\
\hline & & & Max load & 187.2 & 107.1 & 160.3 \\
\hline
\end{tabular}

reduction in relation to the operation of emergency generators during the summer and winter peak times are presented in Table 5 .

\subsubsection{Emergency generator fuel cost:}

In this study, $415 \mathrm{KRW} / \mathrm{kWh}$ was applied as the fuel cost considering the operational efficiency of emergency generators with a capacity of $750 \mathrm{~kW}$ and higher. Most emergency generators use diesel fuel. By applying this generation fuel cost unit price, the yearly fuel cost can be calculated according to the VPP-converted emergency generator scenarios. The results are summarized in Table 6 .

\subsubsection{Price reduction benefits:}

To calculate the benefits of the electricity price reduction for customers, the electricity charges announced by the Korea Electric Power Corporation on January 14, 2013 were applied, as shown in Table 7. This calculation is based on the rate schedule largely chosen by consumers that use emergency generators with a capacity of $750 \mathrm{~kW}$ and higher.

If participating customers operate emergency generators, the electricity rate cuts are expressed as the sum of the benefits from a flat rate reduction and the benefits from a power consumption rate reduction. However, consumers 
Table 8. Benefits from the electricity rate cuts for customers (Million KRW)

\begin{tabular}{c|c|c|c}
\hline \multirow{2}{*}{ Year } & \multicolumn{3}{|c}{ Scenario } \\
\cline { 2 - 4 } & Conservative & Standard & Proactive \\
\hline 2015 & 125 & 188 & 251 \\
\hline 2016 & 314 & 471 & 627 \\
\hline 2017 & 565 & 847 & 1,129 \\
\hline 2018 & 878 & 1,317 & 1,757 \\
\hline 2019 & 1,255 & 1,882 & 2,509 \\
\hline 2020 & 1,819 & 2,729 & 3,639 \\
\hline 2021 & 2,698 & 4,046 & 5,395 \\
\hline 2022 & 4,078 & 6,117 & 8,155 \\
\hline 2023 & 5,740 & 8,610 & 11,480 \\
\hline 2024 & 7,559 & 11,339 & 15,119 \\
\hline 2025 & 9,441 & 14,162 & 18,883 \\
\hline 2026 & 11,323 & 16,985 & 22,647 \\
\hline 2027 & 13,205 & 19,808 & 26,411 \\
\hline 2028 & 15,087 & 22,631 & 30,175 \\
\hline 2029 & 16,969 & 25,454 & 33,939 \\
\hline 2030 & 18,851 & 28,277 & 37,703 \\
\hline
\end{tabular}

Table 9. Demand response participation service benefits (Million KRW)

\begin{tabular}{c|c|c|c}
\hline \multirow{2}{*}{ Year } & \multicolumn{3}{|c}{ Scenario } \\
\cline { 2 - 4 } & Conservative & Standard & Proactive \\
\hline 2015 & 862 & 1,292 & 1,723 \\
\hline 2016 & 2,154 & 3,231 & 4,308 \\
\hline 2017 & 3,877 & 5,816 & 7,755 \\
\hline 2018 & 6,031 & 9,047 & 12,063 \\
\hline 2019 & 8,616 & 12,925 & 17,233 \\
\hline 2020 & 12,494 & 18,741 & 24,988 \\
\hline 2021 & 18,525 & 27,788 & 37,051 \\
\hline 2022 & 28,003 & 42,005 & 56,007 \\
\hline 2023 & 39,420 & 59,130 & 78,840 \\
\hline 2024 & 51,914 & 77,871 & 103,828 \\
\hline 2025 & 64,839 & 97,258 & 129,677 \\
\hline 2026 & 77,763 & 116,645 & 155,527 \\
\hline 2027 & 90,688 & 136,032 & 181,376 \\
\hline 2028 & 103,613 & 155,419 & 207,225 \\
\hline 2029 & 116,537 & 174,806 & 233,074 \\
\hline 2030 & 129,462 & 194,193 & 258,924 \\
\hline & & & \\
\hline
\end{tabular}

can operate emergency generators to reduce the use of maximum peak electricity, which needs to be distinguished from an operation performed at the request of VPP service providers. In this study, the benefits from electricity rate cuts are summarized in Table 8, considering only a power consumption reduction caused by the operation of emergency generators for VPP.

\subsubsection{Demand response participation incentives:}

Based on the 2013 smart demand response service model of South Korea, the VPP participation service benefits were calculated in this study. The annual service benefits for VPP service providers are shown in Table 9.

\subsubsection{Cost for management system construction when distributing emergency generator VPP:}

Table 10 shows the annual costs required for constructing and operating the VPP system. Construction costs increase
Table 10. VPP system construction and operation cost (Million KRW)

\begin{tabular}{c|c|c|c}
\hline \multirow{2}{*}{ Year } & \multicolumn{3}{|c}{ Scenario } \\
\cline { 2 - 4 } & Conservative & Standard & Proactive \\
\hline 2015 & 746 & 844 & 942 \\
\hline 2016 & 789 & 908 & 1,028 \\
\hline 2017 & 795 & 918 & 1,040 \\
\hline 2018 & 811 & 941 & 1,071 \\
\hline 2019 & 863 & 1,019 & 1,175 \\
\hline 2020 & 1,019 & 1,253 & 1,487 \\
\hline 2021 & 1,279 & 1,643 & 2,007 \\
\hline 2022 & 1,695 & 2,267 & 2,839 \\
\hline 2023 & 1,929 & 2,618 & 3,307 \\
\hline 2024 & 2,059 & 2,813 & 3,567 \\
\hline 2025 & 2,056 & 2,808 & 3,561 \\
\hline 2026 & 2,056 & 2,808 & 3,561 \\
\hline 2027 & 2,056 & 2,808 & 3,561 \\
\hline 2028 & 2,001 & 2,726 & 3,451 \\
\hline 2029 & 2,001 & 2,726 & 3,451 \\
\hline 2030 & 2,001 & 2,726 & 3,451 \\
\hline
\end{tabular}

in 2020 when distribution begins increasing in earnest, which is caused by a rise in the terminal equipment cost for emergency generator management as the number of VPPconverted emergency generators increases.

\subsection{Economic efficiency analysis}

The economic efficiency analysis of the VPP distribution model conducted in this study was based on the California Test, which is widely used as a test method for assessing the economic efficiency of load management programs. Economic efficiency was analyzed under the assumption that VPP service providers pay the cost incurred for emergency generator remodeling and the fuel cost. The discount rate for present value applied was $5.5 \%$ based on previous studies of economic efficiency [12].

\subsubsection{Power company's point of view:}

The benefit from the perspective of power companies is represented by the sum of the avoided benefits of equipment and the avoided benefits of purchased power. The latter are expressed as the sum of (1) the amount of self-purchase cost reduction caused by a decrease in demand for load with the operation of VPP-based emergency generators and (2) the SMP reduction because of the decreased load for the corresponding time period. Since fuel cost and the other operating costs incurred for the remodeling and operation of emergency generators are borne by VPP service providers, power companies do not incur a cost. However, the reduction in electricity sales profit because of the operation of emergency generators occurs as a negative benefit. Because power companies do not incur an extra cost, a $\mathrm{B} / \mathrm{C}$ ratio analysis was not performed and the benefit factor alone was calculated as shown in Table 11. 
Table 11. Power company benefits in NPV (Million KRW)

\begin{tabular}{c|c|c|c}
\hline \multirow{2}{*}{ Year } & \multicolumn{3}{|c}{ Scenario } \\
\cline { 2 - 4 } & Conservative & Standard & Proactive \\
\hline 2015 & 1,614 & 2,422 & 3,229 \\
\hline 2016 & 3,826 & 5,738 & 7,651 \\
\hline 2017 & 6,527 & 9,791 & 13,054 \\
\hline 2018 & 9,624 & 14,436 & 19,248 \\
\hline 2019 & 13,032 & 19,548 & 26,064 \\
\hline 2020 & 17,911 & 26,867 & 35,822 \\
\hline 2021 & 25,173 & 37,760 & 50,347 \\
\hline 2022 & 36,069 & 54,103 & 72,138 \\
\hline 2023 & 48,127 & 72,190 & 96,254 \\
\hline 2024 & 60,076 & 90,114 & 120,152 \\
\hline 2025 & 71,121 & 106,682 & 142,242 \\
\hline 2026 & 80,851 & 121,277 & 161,703 \\
\hline 2027 & 89,374 & 134,061 & 178,747 \\
\hline 2028 & 96,788 & 145,182 & 193,575 \\
\hline 2029 & 103,186 & 154,779 & 206,372 \\
\hline 2030 & 108,654 & 162,981 & 217,308 \\
\hline
\end{tabular}

Table 12. Benefits and Costs in NPV from a VPP Service Provider's Point of View (Million KRW)

\begin{tabular}{c|c|c|c|c|c|c}
\hline \multirow{2}{*}{ Year } & \multicolumn{2}{|c|}{ Present value of benefit } & \multicolumn{2}{c}{ Present value of costs } \\
\cline { 2 - 7 } & $\begin{array}{c}\text { Conser- } \\
\text { vative }\end{array}$ & Stan-dard & Pro-active & $\begin{array}{c}\text { Conser- } \\
\text { vative }\end{array}$ & $\begin{array}{c}\text { Stan- } \\
\text { dard }\end{array}$ & $\begin{array}{c}\text { Pro- } \\
\text { active }\end{array}$ \\
\hline 2015 & 862 & 1,292 & 1,723 & 2,465 & 3,422 & 4,379 \\
\hline 2016 & 2,042 & 3,063 & 4,084 & 3,349 & 4,762 & 6,175 \\
\hline 2017 & 3,484 & 5,225 & 6,967 & 4,175 & 6,016 & 7,856 \\
\hline 2018 & 5,137 & 7,705 & 10,273 & 4,985 & 7,243 & 9,501 \\
\hline 2019 & 6,955 & 10,433 & 13,911 & 5,796 & 8,471 & 11,147 \\
\hline 2020 & 9,559 & 14,339 & 19,119 & 7,966 & 11,739 & 15,511 \\
\hline 2021 & 13,435 & 20,153 & 26,871 & 11,397 & 16,896 & 22,395 \\
\hline 2022 & 19,251 & 28,876 & 38,501 & 16,613 & 24,730 & 32,847 \\
\hline 2023 & 25,686 & 38,529 & 51,372 & 19,609 & 29,233 & 38,858 \\
\hline 2024 & 32,064 & 48,095 & 64,127 & 21,352 & 31,858 & 42,364 \\
\hline 2025 & 37,959 & 56,938 & 75,917 & 22,149 & 33,062 & 43,976 \\
\hline 2026 & 43,152 & 64,727 & 86,303 & 22,376 & 33,411 & 44,447 \\
\hline 2027 & 47,700 & 71,550 & 95,400 & 22,519 & 33,634 & 44,749 \\
\hline 2028 & 51,657 & 77,486 & 103,314 & 22,559 & 33,702 & 44,844 \\
\hline 2029 & 55,072 & 82,608 & 110,144 & 22,560 & 33,710 & 44,860 \\
\hline 2030 & 57,990 & 86,985 & 115,980 & 22,499 & 33,625 & 44,752 \\
\hline
\end{tabular}

\subsubsection{VPP Service provider's point of view:}

The benefit model of emergency generator-based VPP service providers (participants) is an incentive acquired by participating in the demand response market based on emergency generator resources, and it is expressed as the sum of (1) the basic payment for the mandatory reduction and (2) the performance payment for the reduction in accordance with the reduction command. On the contrary, cost factors comprise the emergency generator remodeling cost and emergency generator fuel and system costs incurred by the reduction command.

In terms of the benefits from a VPP service provider's point of view, the initial business stage generates many cost factors; however, the benefits exceed the costs around after 2018 as the cumulative capacity of the emergency generator resources acquired in the initial stage continues to increase. Fig. 3 illustrates that the $\mathrm{B} / \mathrm{C}$ ratio of a VPP service provider will be greater than 1 after 2020 (i.e., about six years after starting the business) [12].

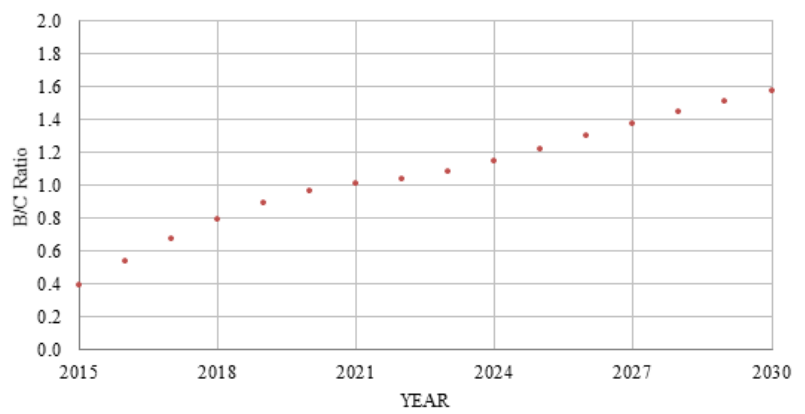

Fig. 3. B/C ratio of VPP service providers (Standard distribution scenario)

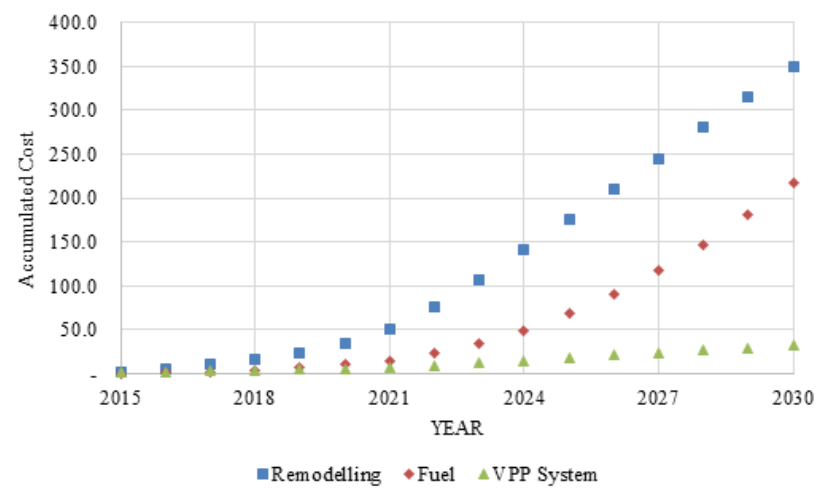

Fig. 4. Yearly accumulated costs by VPP cost Item (Billion KRW)

Fig. 4 shows the yearly accumulated cost of a VPP system and fuel cost as well as the emergency generator remodeling cost in order to investigate the proportion of the main cost factors for VPP cost items.

The emergency generator remodeling cost and fuel cost comprise the vast majority of a VPP service provider's cost factors. By contrast, the VPP system construction and operation costs account for only a small proportion. Therefore, it is necessary to curtail fuel or remodeling costs in order to enhance feasibility.

\subsection{Sensitivity analysis}

Although various factors affect the economic efficiency of emergency generator-based VPP, this study conducted a sensitivity analysis in relation to payment price from the perspective of a VPP service provider. Payment for the mandatory reduction is settled based on the monthly basic price for the mandatory reduction capacity. Sensitivity was analyzed only for the standard distribution scenario.

\subsubsection{Analysis of sensitivity to basic price changes:}

Table 13 reports the sensitivity analysis results with basic price change rates at $80 \%, 60 \%$, and $40 \%$ based on the capacity subsidy price in the demand response market as of 2013 in South Korea, which is 51,200 KRW/kW. 
Table 13. Sensitivity to basic price changes

\begin{tabular}{c|c|c|c}
\hline $\begin{array}{c}\text { Basic price change rate } \\
(\mathrm{KRW} / \mathrm{kW})\end{array}$ & $\begin{array}{c}\text { Present value of total } \\
\text { benefits [million KRW] }\end{array}$ & $\mathrm{B} / \mathrm{C}$ & $\begin{array}{c}\text { NPV } \\
\text { [million KRW] }\end{array}$ \\
\hline $100 \%(51,200)$ & $618,005.4$ & 1.8 & $272,409.5$ \\
\hline $80 \%(40,960)$ & $556,800.9$ & 1.6 & $211,286.0$ \\
\hline $60 \%(30,720)$ & $495,596.3$ & 1.4 & $150,081.4$ \\
\hline $40 \%(20,480)$ & $434,391.7$ & 1.3 & $88,876.8$ \\
\hline
\end{tabular}

Table 14. Sensitivity to performance price changes

\begin{tabular}{c|c|c|c}
\hline $\begin{array}{c}\text { Performance price } \\
\text { change rate } \\
(\mathrm{KRW} / \mathrm{kWh})\end{array}$ & $\begin{array}{c}\text { Present value of total } \\
\text { benefits [million KRW] }\end{array}$ & B/C & $\begin{array}{c}\text { NPV } \\
\text { [million KRW] }\end{array}$ \\
\hline $100 \%(543.72)$ & $618,005.4$ & 1.8 & $272,409.5$ \\
\hline $80 \%(434.98$ & $556,608.9$ & 1.6 & $210,094.0$ \\
\hline $60 \%(326.23)$ & $493,212.4$ & 1.4 & $147,697.5$ \\
\hline $40 \%(217.49)$ & $430,815.9$ & 1.2 & $85,301.0$ \\
\hline
\end{tabular}

Table 15. Sensitivity to remodeling cost price changes

\begin{tabular}{c|c|c|c}
\hline $\begin{array}{c}\text { Remodeling cost price } \\
\text { changes (KRW/kW) }\end{array}$ & $\begin{array}{c}\text { Present value of total } \\
\text { costs [million KRW] }\end{array}$ & B/C & $\begin{array}{c}\text { NPV } \\
\text { [million KRW] }\end{array}$ \\
\hline $100 \%(93,147)$ & $345,514.9$ & 1.8 & $272,409.5$ \\
\hline $80 \%(74,518)$ & $304,194.4$ & 2.0 & $313,811.0$ \\
\hline $60 \%(55,888)$ & $262,873.9$ & 2.4 & $355,131.5$ \\
\hline $40 \%(37,259)$ & $221,553.5$ & 2.8 & $396,452.0$ \\
\hline
\end{tabular}

Table 16. Sensitivity to fuel cost price changes

\begin{tabular}{c|c|c|c}
\hline $\begin{array}{c}\text { Fuel cost price changes } \\
(\mathrm{KRW} / \mathrm{kW})\end{array}$ & $\begin{array}{c}\text { Present value of total } \\
\text { costs [million KRW] }\end{array}$ & $\mathrm{B} / \mathrm{C}$ & $\begin{array}{c}\text { NPV } \\
\text { [million KRW] }\end{array}$ \\
\hline $100 \%(518.8)$ & $375,280.4$ & 1.6 & $242,725.0$ \\
\hline $80 \%(415.0)$ & $345,514.9$ & 1.8 & $272,409.5$ \\
\hline $60 \%(311.3)$ & $315,749.4$ & 2.0 & $302,256.0$ \\
\hline $40 \%(207.5)$ & $285,983.9$ & 2.2 & $332,021.5$ \\
\hline
\end{tabular}

\subsubsection{Analysis of sensitivity to performance price changes:}

Table 14 reports the sensitivity analysis results with performance price change rates at $80 \%, 60 \%$, and $40 \%$ based on the capacity subsidy price in the demand response market as of 2013 in South Korea, which is 543.72 $\mathrm{KRW} / \mathrm{kWh}$.

\subsubsection{Analysis of sensitivity to remodeling cost price changes:}

The emergency generator remodeling cost includes the CTTS remodeling and load remodeling costs. The remodeling cost gradually decreases as the VPP project is distributed through emergency generator remodeling. The cost and $\mathrm{B} / \mathrm{C}$ changes are summarized in Table 15 , with the remodeling cost applied at $80 \%, 60 \%$, and $40 \%$ based on the remodeling cost proposed in this study. The present value of the total benefits is 618,005 million KRW.

\subsubsection{Analysis of sensitivity to fuel cost price changes:}

Costs and benefits were calculated with the fuel cost incurred for emergency generator operation and calculated at $415 \mathrm{KRW} / \mathrm{kW}$. The results of the sensitivity calculation

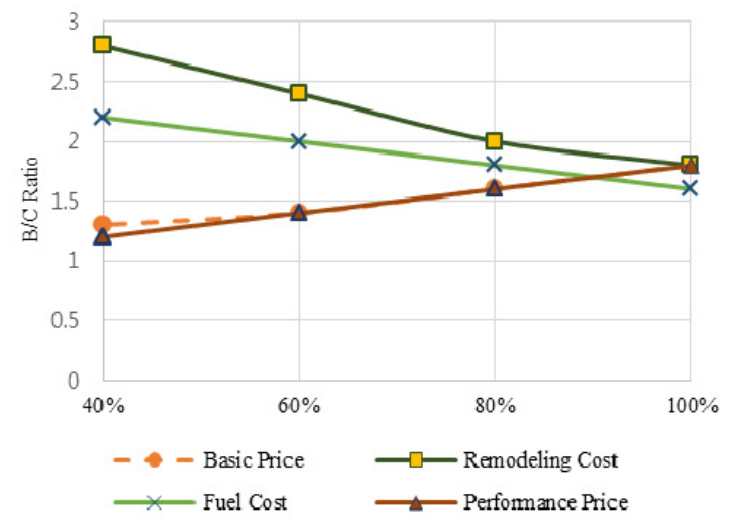

Fig. 5. Analysis of $\mathrm{B} / \mathrm{C}$ sensitivity to price changes

according to fuel cost price changes with the fuel cost being set to $80 \%$ are shown in Table 16 .

Fig. 5 shows the $\mathrm{B} / \mathrm{C}$ ratio changes according to the changes in basic payment, performance payment, remodeling cost, and fuel cost price. It shows that the remodeling cost price is the most sensitive to price changes.

\section{Conclusion}

This study analyzed the economic efficiency of the emergency generator-based VPP model by calculating the main costs and benefits. An economic efficiency analysis was performed in a way that the remodeling costs for converting emergency generators into demand response resources and the fuel costs for operating the emergency generators associated with demand response are borne by VPP service providers. The results of the presented economic efficiency analysis showed that VPP service providers reach the breakeven point six years after starting the business. In order to enhance feasibility for VPP service providers, an analysis of sensitivity to factors affecting feasibility was also conducted. The basic payment price, fuel cost for emergency generator operation, and remodeling cost for emergency generators were regarded as the main items. Based on this, $\mathrm{B} / \mathrm{C}$ ratio volatility was analyzed, especially when these items are changed. The results showed that the $\mathrm{B} / \mathrm{C}$ ratios are greater than 1 when volatility is applied separately to each item, which implies business feasibility. However, factors largely affecting the $\mathrm{B} / \mathrm{C}$ ratio were the emergency generator remodeling cost and basic payment price. Among these, the cost savings from the remodeling cost, which is easy to control from a service provider's standpoint, are a major factor to ensure profitability. The findings of this study thus revealed that emergency generator-based VPP is an effective model that offers easy-to-secure resources in terms of economic efficiency. However, for practical applications, additional factors such as the environment and subsidy policy need to be considered. 


\section{Acknowledgements}

This work was supported by the Power Generation and Electricity Delivery Core Technology Program of the Korea Institute of Energy Technology Evaluation and Planning(KETEP) granted financial resource from the Ministry of Trade, Industry \& Energy, Republic of Korea. (20131010501760)

\section{References}

[1] S. You, C. Træholt, and B. Poulsen, "Generic virtual power plants: Management of distributed energy resources under liberalized electricity market," 8th IET International Conference on Advances in Power System Control, Operation and Management, Hong Kong, China: Institution of Engineering and Technology, 2009.

[2] P. Lombardi, M. Powalko, and K. Rudion, "Optimal operation of a virtual power plant," presented at the IEEE Power \& Energy Society General Meeting, Calgary, Canada, 2009.

[3] KEPCO Economy Management Research Institute, "A Study on Operation Status and Utilization of Customer Owned Emergency Generators," 1997.

[4] KEPCO, "A Study on Utilization of Customer Owned Generators for Demand Side Management," 2012.

[5] J. Choi, J. Jung, J. Lim, S. Ma, and K. Park, "A Study on Utilization of Backup Generators for Demand Side Management," KIEE Power Engineering Society Conference, 2012.

[6] Korea Smart Grid Institute, "A Study on Technology and Policies for Backup Generators based VPP," 2013.

[7] KPX, "2012 Electricity Market Trends and Analysis," 2014.

[8] Korea Ministry of Knowledge Economy, "The Sixth Basic Plan for Long-term Electricity Supply and Demand," 2013

[9] KPX, "Power market operation regulations," 2014

[10] KEPCO, "Execution Plan for Demand Side Management," 2012.

[11] Korea Ministry of Knowledge Economy, "Evaluation Report for Demand Side Management," 2010.

[12] Korea Development Institute, "A Study on General Guidelines for Pre-feasibility Study (5th Edition)," 2008.

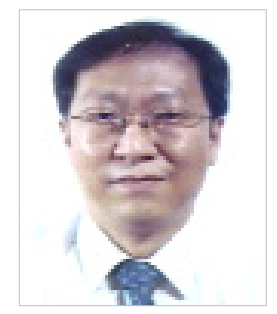

Beom-Jin Chung He received M.S degree in electrical engineering from Seoul National University and Ph.D. degree in Electronics \& Information Engineering from Graduate School of Hankook University of Foreign Studies Korea, in 2014. He is a research professor in Smart Green Home Research

Center, Gachon University. His research interests are industrial network and power System operation and planning in smart grid.

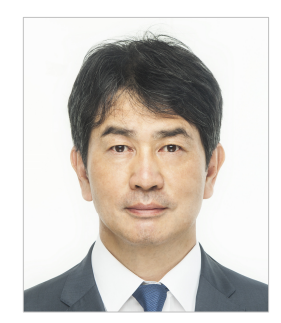

Chang Seob Kim He received the B.S., M.S. and Ph.D. degrees from Seoul National University 1984, 1986 and 1990 , respectively. He is a professor in the Department of Energy IT, Gachon University, Korea.

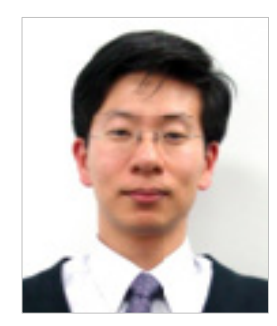

Sung-Yong Son He received the B.S. and M.S. degrees from Korea Advanced Institute of Science and Technology (KAIST), Korea in 1990 and 1992, respectively, and Ph.D. degree in Mechanical Engineering from University of Michigan, Ann Arbor, in 2000. From 2000 to 2005 , he worked at $4 \mathrm{DHomeNet}$ and Icross-technology, respectively. He is an associate professor in the Department of Electrical Engineering and the director of Smart Green Home Research Center, Gachon University, Korea. His main research interests include smart grid and smart home. 